\title{
Ideología, Ciencia y Trabajo Social ${ }^{1}$
}

\section{Ana Laura Elorza}

Licenciada en Trabajo Social (UNC)

Doctora en Trabajo Social (UNCuyo)

Investigadora del Instituto de Investigación

de la Vivienda y Hábitat (FAUD)

Becaria CONICET

E-mail: analauraelorza@hotmail.com

1 Este trabajo es una adaptación del práctico realizado en el marco del curso de postgrado "Debates actuales en epistemología” dictado por el Dr. Follari en la Facultad de Filosofía y Humanidades de la Universidad Nacional de Córdoba en el año 2011. 
Resumen

Los imaginarios y representaciones referidos a la ciencia se han configurado a partir de su oposición a la ideología, fundamentados en la concepción que las prácticas de generación de nuevos conocimientos deben ser neutrales y objetivas para alcanzar un conocimiento valido y confiable. Aunque esta concepción es ampliamente criticada aún sigue vigente, por lo que abordamos la relación entre ideología y ciencia buscando conocer las distintas modalidades en las que se fue configurando dicha relación y cómo ésta se ha definido en el Trabajo Social.

Palabras clave

Ideología - Ciencia y Trabajo Social
Abstract

The imaginary and representations concerning science are configured from its opposition to the ideology, based on the conception that the practices of generating new knowledge should be neutral and objective to achieve a valid and reliable knowledge. Although this view is widely criticized still in force, so we address the relationship between ideology and science seeking to know the different ways in which this relationship took shape and how it is defined in Social Work.

Key words

Ideology - Science and Social Work 


\section{Introducción}

A lo largo del tiempo y la historia, por lo general, los imaginarios y representaciones referidos a la ciencia se han configurado a partir de su oposición a la ideología, fundamentados en la concepción que las prácticas de generación de nuevos conocimientos deben ser neutrales y objetivas para alcanzar un conocimiento valido y confiable. Esta suposición fue extendida al rol de los investigadores y profesionales, en los que se privilegia su perfil técnico-academicista sobre el ético-político.

Aunque esta concepción es ampliamente criticada aún sigue vigente. Por este motivo, en el presente trabajo abordamos la relación entre ideología y ciencia buscando conocer las distintas modalidades en las que se fue configurando dicha relación y cómo ésta se ha definido en el Trabajo Social.

Este ensayo se estructura de la siguiente manera: en primer lugar, desarrollamos sintéticamente los cambios de sentido producidos en torno al concepto ideología a lo largo de la historia; en segundo lugar, establecemos las vinculaciones entre la ideología y la ciencia, y cómo esta relación es intrínseca a los sujetos y al trabajo de generación de conocimientos; por último, reflexionamos sobre las distintas perspectivas teóricas e ideológicas que han ido configurando el rol de la profesión y la posición ético-política de los trabajadores sociales.

\section{Aproximación conceptual a la Ideología}

El concepto de ideología se fue modificando históricamente, por consiguiente su significado puede entenderse sólo si se reconoce su reconfiguración histórica. Adorno y Horkheimer (1973) plantean que las condiciones generales de la comprensión de la ideología como una "falsa conciencia" son puestas de relieve a comienzos de la moderna sociedad burguesa, entre fines del siglo XVI y principios del XVII ${ }^{1}$.

1 Plantean que los elementos conceptuales que provienen de la prehistoria del concepto de ideología 
Estos autores hacen un análisis de las diferentes interpretaciones que se han producido desde esa época al concepto de ideología, algunas de las cuales son: Francis Bacon, en busca de la liberación de la razón, proclama la lucha contra los “idola", entendiéndolos como los prejuicios colectivos; Helvecio y Holbach, declaran que estos prejuicios cumplen una determinada función social, la del mantenimiento de la injustica y obstaculizan la edificación de una sociedad racional; Destutt de Tracy de la escuela francesa de les idéologues (a quien se le debe el término "ideología”), propone que frente al método científico, la falsa conciencia debía desaparecer, suponía que era suficiente poner orden en la conciencia para ordenar la sociedad.

Con esta última concepción comienza a construirse la relación antagónica entre ciencia e ideología, a través de la cual, por un lado, se legitima el orden social al no reconocer el "desorden" por las determinaciones de la estructura del capitalismo, y por el otro, se le atribuye a la ciencia la capacidad de ordenar la sociedad, un rol ambicioso y a la vez inalcanzable.

Por otra parte, desde la tradición teórica marxista, la ideología es una de las instancias de la superestructura de la sociedad (religiosa, moral, política, etc.) y comprende como una realidad, indispensable para la producción y reproducción del capitalismo. En este sentido, Althusser (1969) explica que para la reproducción de la fuerza de trabajo no solo es necesario la reproducción de su calificación (es decir, ser competente para distintas tareas definidas según la división socio-técnica del trabajo), sino también la reproducción de su sumisión a las reglas del orden establecido. Esto implica un doble proceso integrado, por un lado, el sometimiento por parte del sector dominado a la ideología dominante y, por el otro, una reproducción de la capacidad de un buen manejo de la ideología dominante por parte de los agentes de la explotación, asegurándose su predominio de clase. Distintas instituciones como la escuela, la iglesia, el Estado, medios de comunicación, entre otros, a través de la difusión de las normas y 
valores culturales, son los responsables del sometimiento ideológico de los sectores dominados.

Follari et al (1984), sintetizando los antecedentes en la teorización sobre la ideología, avanza en su esclarecimiento conceptual y la define como el conjunto de significaciones acerca del mundo que un sujeto "porta"; y aclara que desde esta definición básica, se desprenden dos concepciones centrales. La primera, entendiéndola como "falsa conciencia”, como se expuso en párrafos anteriores, una versión equivocada de lo que es la realidad, esta idea se vincula con el desconocimiento. Así, la ideología se opondría a al conocimiento "verdadero" del mundo, el cual estaría desideologizado. La segunda, señala a la ideología como elemento constituyente de cualquier discurso posible, esta definición contempla la producción de ideologías, tanto de dominadores como dominados (Follari et al, 1984:61).

Compartimos esta posición de comprender a la ideología desde la segunda concepción, al entender que existen ideologías, se asume la lucha entre clases sociales y las estructuras institucionales que éstas montan en su proceso de constitución, diferenciación y enfrentamientos. Podríamos decir de manera general, que las ideologías remiten a dos polos: la que propugna por el mantenimiento del orden establecido y la que propone su modificación hacia un modo de producción diferente (Follari et al, 1984:62).

Así como la sociedad se encuentra en permanente movimiento, la ideología no puede ser confundida como un sistema petrificado de ideas (Iamamoto, 1997), por el contrario, se encuentra en permanente proceso de definición a través de la lucha de clases, configurándose procesos de reproducción y ruptura. Sin embargo, hay que destacar que la ideología que domina en una sociedad es la de los sectores dominantes, la cual se presenta como "neutra" basada en principios de libertad, igualdad y democracia. Ésta se interioriza de manera "inconsciente", debido a su producción y transmisión, a través de las instituciones identificadas como "aparatos ideológicos" (escuela, familia, Estado, etc.) y de las diferentes prácticas sociales producidas en toda la sociedad. 
En este sentido, la ideología dominante es un medio de obtención del consentimiento de los dominados, adaptándolos al orden vigente; su difusión y reproducción remite a una de las formas de control social. Sin embargo, como plantea Iamamoto (1997), a pesar de la fuerza de la ideología en la obtención del consentimiento de los oprimidos en la medida en que encubre y legitima la explotación, su eficacia es limitada: "sí encubre las contradicciones en y para la conciencia, no las elimina" (Iamamoto, 1997:128). Ahí radica la posibilidad de construcción de otras ideologías resistentes, que luchan por la modificación del orden social establecido.

\section{Ideología y ciencia}

Desde la escuela francesa de les idéologues la noción de la ideología como oposición de la ciencia ha sido muy difundida; ésta se fundamenta en comprender a la ciencia en oposición al sentido común y a los saberes cotidianos. Se sostiene que la ciencia genera nuevos conocimientos a través del modelo newtoniano -que implica: descubrimiento de leyes naturales que gobiernan el universo a través de la investigación empírica que incluye mediciones, fórmulas matemáticas, deducciones lógicas, etc. (Wallerstein, 2002)- y gracias a este mecanismo este tipo de conocimiento estaría libre de ideologías. Sin embargo, es esa pretensión de la ciencia de constituirse en metadiscurso de lo "verdadero" la que lo constituye como ideología dominante.

Pero si, como mencionamos anteriormente, las ideologías se encuentran en permanente producción y reproducción, también esta disputa se produce en el campo científico. Muchos investigadores proponen nuevas perspectivas en la definición de qué se entiende por ciencia y su rol en la sociedad. Uno entre tantos es Sousa Santos (2009), quien a partir de la crítica al conocimiento científico occidental, lo que él denomina como conocimiento de regulación, propone la “ecología de saberes" basado en la idea de que conocimientos heterogéneos pueden coexistir e implica posicionarnos de qué lado estamos: de los opresores o de los oprimidos. 
Por todo lo antes mencionado, sostenemos que la ciencia no puede identificarse con un conocimiento neutral y objetivo, ya que es una invención del hombre, determinada por ciertos procesos históricosociales definidos (Follari, 1984:69), es decir, el conocimiento es un fenómeno social e intersubjetivo.

Sobran ejemplos para ilustrar la capacidad que tiene la ciencia a la hora de legitimar su práctica y discurso, en detrimento de otros saberes, conocimientos y prácticas; y que brinda fundamentos para la definición de acciones político-económicas. Desde las ciencias sociales, podemos mencionar la fuerte influencia del funcionalismo en la década del sesenta, para fundamentar políticas de corte desarrollista que en el plano de las políticas sociales propugnaba un cambio de conductas y valores culturales de los sectores populares para la superación de la pobreza; pero también algunas teorizaciones han servido en la fundamentación de la ideología de los sectores dominados, como el caso del movimiento de trabajadores que encontró las herramientas teóricas y metodológicas para comprender los procesos de producción y reproducción social de la cuestión social a partir de los aportes de Marx; quien revela que la misma está determinada por la relación capital/trabajo y que para su superación es necesario transformar los dispositivos explotadores del régimen capitalista (Netto, 2003).

Volcando el análisis en un plano más operativo del trabajo de un investigador social ¿cómo se manifiesta la ideología en nuestras prácticas? Esta se encuentra en el plano axiológico, ontológico y epistemológico de la tarea emprendida. En particular, en cada trabajo, la definición de los objetivos y el posicionamiento teórico nos dan cuenta de la ideología del investigador.

Aceptar la indisoluble relación ciencia-ideología nos remite a un posicionamiento diferente y de mayor honestidad, emprender el trabajo de ser objetivos pero no neutrales. "La objetividad es usar todas las metodologías que nos permitan analizar, con distancia crítica, todas las perspectivas posibles de una cierta realidad social. Y las metodologías de las ciencias sociales pueden ser útiles, son muy útiles para crear objetividad, para limitar el dogmatismo, para limitar 
un encierro ideológico, para mantener una distancia crítica, pero sin neutralidad, siempre preguntando de qué lado estamos” (Sousa Santos, 2009:156).

\section{Ideología y Trabajo Social}

Como plantea Iamamoto (1997), si bien el Trabajo social en su trayectoria no adquiere el status de ciencia, esto no significa que sea posible y necesario producir conocimientos desde la disciplina, contribuyendo para el acervo de las ciencias sociales y también en articulación dinámica entre teoría y práctica.

Podemos considerar a los profesionales trabajadores sociales como intelectuales, intelectuales subalternos al ser administradores y divulgadores de la riqueza intelectual existente, tradicionalmente acumulada (Gramsci apud Iamamoto, 1997:103); por lo que el debate de la relación entre ciencia e ideología es central en la definición de las teorías y perspectivas y posicionamiento ideológico desde las cuales se diseña la intervención social y se abordan las investigaciones sociales ${ }^{2}$.

La especificidad profesional se ha ido configurando de diferentes formas según el momento socio-histórico. En sus inicios, se conformó como una disciplina complementaria a otras (medicina, abogacía, etc.), orientada a la colaboración en vinculación de los profesionales con la población pobre; este rol era asumido, por lo general por mujeres, como una misión filantrópica y moral. En oposición a esta concepción y después de revisiones de la actuación profesional, en los años sesenta el Movimiento de Reconceptualización redefine la actuación profesional hacia la promoción el "cambio social". Posteriormente, con el arribo neoliberal en el modelo del Estado y en la definición de las políticas, en especial, las políticas sociales comienzan a ser "focalizadas", destinadas sólo para los sectores identi-

2 Actividad que en los últimos años se ha ido consolidando en los distintos espacios académicos del país (Wagner, 2013). 
ficados como pobres, por lo que el trabajador social como "técnico" debe garantizar la administración de los recursos a la población más vulnerable.

Estas posturas ${ }^{3}$ manifiestan distintas ideologías respecto a la visión del mundo y de los problemas sociales, en general, y al rol de la profesión, en particular. Sin embargo, el imaginario existente en torno al perfil de los trabajadores sociales es el de personas (en su mayoría mujeres) con alto compromiso con la sociedad, independiente y en busca de brindar ayuda a los sectores más vulnerables elige esta profesión. Poder cuestionar esta representación atribuida al trabajo social es esencial para comprender la vinculación existente entre el modelo de producción, nuestro trabajo y la disputa entre las clases.

Realizando un análisis crítico respecto a la profesión y a las distintas atribuciones que se han producido en torno a ésta, Iamamoto (1997) propone considerar al Trabajo Social desde dos ángulos: como realidad vivida y realidad presentada en y por la conciencia de sus agentes profesionales expresada por el discurso teórico-ideológico sobre el ejercicio profesional; y como actividad socialmente determinada por las circunstancias sociales objetivas que confieren una dirección social a la práctica profesional, los que condiciona y sobrepasa la voluntad y/o conciencia de sus agentes individuales (Iamamoto, 1997:87). Esta doble dimensión presenta sus contradicciones, expresándose ésta en la distancia y el desfasaje entre las intenciones expresadas en el discurso que ratifica el quehacer y el propio ejercicio de esa actividad, muchas veces es vivido por los profesionales como frustración en su desarrollo profesional.

Sin embargo, esto se debe a los propios orígenes de la profesión, ya que se institucionaliza dentro de la división capitalista del trabajo, como actor en la implementación de las políticas sociales llevadas a cabo por organismos públicos y privados, inscriptos en el esfuerzo de la legitimación del poder de grupos y fracciones de las clases dominantes que controlan el aparato estatal. En la operacionalización de

3 No han sido las únicas, a los fines de este trabajo sólo mencionamos estas y con ciertos matices siguen vigentes en las representaciones atribuidas a la profesión. 
medidas instrumentales de control social, el empleo de técnicas y tecnologías sociales es ampliamente utilizado, como medios de influenciar la conducta humana, adecuándolos a los estándares legitimados de la vida social, previniendo y canalizando la expresión de tensiones para los canales institucionales (Iamamoto, 1997:128).

En este sentido, la profesión se constituye como vehículo de producción y reproducción de la ideología dominante, a través de las acciones de tipo socio-educativo, impulsadas para lograr cambios en la manera de ser, de sentir, de ver, de actuar de los individuos, en busca de la "integración social".

No obstante, no todo está determinado en el ejercicio de la profesión, dentro del colectivo profesional no podemos decir que existe un modelo de intervención univoco, y la concreción de un proyecto alternativo es uno de los desafíos actuales en una coyuntura políticoeconómica caracterizada por: el impulso de los movimientos sociales en el escenario público, la redirección de la política y programas estatales, y el proceso organizativo del colectivo profesional.

\section{Reflexiones finales}

A pesar que durante mucho tiempo la producción de conocimiento en el campo disciplinar ha sido menospreciada, privilegiándose el aspecto técnico-operativo de la profesión, en los últimos años se observa una consolidación en la participación y desarrollo de trabajo de investigación de los trabajadores sociales. Avance importante, ya que a través de la investigación podemos identificar nuevas demandas y conocer el origen, las determinaciones, impactos y estructura de los problemas (Aquín, 2006; Acevedo, 2006).

En este escenario, repensar la relación entre ciencia e ideología es central, en la definición de las teorías, perspectivas y objetivos de los trabajos se trasluce el posicionamiento ideológico desde el cual se abordan los problemas de estudio y, se diseña la intervención social.

Desnaturalizar la noción de la producción del conocimiento como neutral, rechazar el imaginario y las prácticas conservadoras del 
trabajo social enraizadas en la profesión, y definir nuestra posición ideológica posibilitaría redirigir nuestras práctica al servicio de los intereses y necesidades de los sectores dominados, produciendo colectivamente nuevas fuentes de legitimidad para el desarrollo profesional, también en el campo científico-académico.

\section{Referencias bibliográficas}

ACEVEDO, P. "Investigación e intervención en trabajo Social: revisando supuestos e identificando nuevos escenarios", en: AQUIN, N. (Comp.) Reconstruyendo lo social. Prácticas y experiencias de investigación desde el Trabajo Social. Buenos Aires, Espacio, 2006.

AQUIN, N. "La investigación en el campo del Trabajo Social", en: AQUIN, N. (Comp.) Reconstruyendo lo social. Prácticas y experiencias de investigación desde el Trabajo Social. Buenos Aires, Espacio, 2006.

ADORNO, T. y HORKHEIMER, M. La Sociedad. Lecciones de sociología. Buenos Aires, Editorial Proteo, 1973.

ALTHUSSER, L. Ideología y aparatos ideológicos del Estado. Buenos Aires, Fichas Nueva Visión, 1969.

DE SOUZA SANTOS, B. Pensar el estado y la sociedad: desafíos actuales. Buenos Aires, CLACSO, 2009.

FOLLARI, R. et. al. Trabajo en comunidad: análisis y perspectivas. México, Editorial UAS, 1984.

IAMAMOTO, M. Servicio social y división del trabajo. Brasil. Cortez, 1997.

NETTO, J. P. "Cinco notas a propósito de la 'cuestión social”, en: BORGIANNI et. al. (comp.) Servicio Social Crítico. Hacia la construcción del nuevo proyecto ético-político profesional. Brasil. Cortez, 2003.

WAGNER, A. "La investigación en el trabajo social argentino. Estado de situación" en: ACEVEDO, P. y FUENTES, P. (comp.) La formación académica en trabajo social en la República Argentina: debates y desafíos. Córdoba, UNC-FAUATS, 2013.

WALLERSTEIN, I. Conocer el mundo, saber el mundo. México, Siglo XXI, 2002.

Recepción: 08/04/2015

Aceptación: 02/07/2015 